\title{
Strategi Guru Pendidikan Agama Islam dalam Pembinaan Akhlak Siswa di Sekolah Dasar Negeri 234 Barambang II Maros, Sulawesi Selatan
}

\author{
Adilham \\ Politeknik Pertanian Negeri Pangkajene Kepulauan
}

\begin{abstract}
Abstrak
Penelitian ini bertujuan untuk mengetahui bagaimana strategi guru PAl dalam membina akhlak siswa di SDN Barambang II mengingat mereka sebagai generasi penerus agama, bangsa, dan negara. Penelitian ini menggunakan metode kualitatif deskriptif yaitu pengamatan lapangan terhadap bentuk pembinaan akhlak siswa. Metode pengumpulan data dilakukan melalui observasi, wawancara, dan dokumentasi. Hasil penelitian menunjukkan bahwa strategi guru PAI dalam pembinaan akhlak siswa terbagi ke dalam dua bentuk yaitu pembinaan dalam pembelajaran intrakurikuler dan pembinaan dalam pembelajaran ekstrakurikuler. Strategi guru PAI ini membutuhkan bantuan dan kerjasama dari semua pihak yang terlibat dalam dunia pendidikan, termasuk kepala sekolah, guru- guru kelas, pegawai sekolah, orang tua siswa, dan warga masyarakat sekitar agar tujuan dalam membentuk siswa yang berakhlakul karimah bisa tercapai secara maksimal.
\end{abstract}

Kata Kunci : Pembinaan Akhlak Siswa, Efektivitas Pembinaan Guru PAI

Abstract

This research aims to know how teacher's strategy to build morals of students as such as we know that they are expected to be succes generation of religion, nation, and country. This research used a qualitative descriptive method like field observation to form moral development of students. Data collection method used observation, interview, and documentation. The results of this research showed that strategy of PAI teacher Primary School of 234 Barambang II was divided into two forms namely development moral in intracurricular learning and extracurricular learning. This strategy requires assistance and cooperation of all participants involved in education, including headmaster, school staff, all of classroom teachers, and the residents of surrounding communities by purpose in shaping students' morality and can be achieved maximally.

Keywords : Moral Development of Students, Effectiveness of Islamic Teacher Guidance

\section{PENDAHULUAN}

Kutipan buku Mansur Isna (200I: 38-40) menyatakan bahwa pendidikan secara umum meliputi perbuatan atau semua usaha generasi tua untuk mengalihkan (melimpahkan) pengetahuannya, pengalamannya, kecakapan serta keterampilannya kepada generasi muda sebagai usaha untuk menyiapkan mereka agar dapat memenuhi fungsi hidupnya, baik jasmaniah dan rohaniah. Pendidikan Islam bukan sekedar transfer of knowledge ataupun transfer of training, tetapi lebih merupakan suatu sistem yang ditata di atas fondasi keimanan dan kesalehan.

Menurut Hadari Nawawi (1989: 7) yang bertanggung jawab atas maju dan mundurnya pendidikan, termasuk pendidikan Islam ada pada pundak keluarga(orangtua), sekolah (guru), dan masyarakat. Ketiganya merupakan satu kesatuan yang utuh dan saling melengkapi antara satu dengan yang lain. Namun di era sekarang pendidikan anak seolah- olah sepenuhnya diserahkan kepada lembaga pendidikan formal yaitu sekolah sehingga beban yang dipikul oleh guru sebagai pendidik semakin besar. Hal tersebut menjadikan guru terkhusus kepada guru Pendidikan agama Islam (PAl) yang berperan banyak dalam pembentukan dan pembinaan akhlak siswa.
Anak didik adalah anak yang sedang tumbuh dan berkembang, baik secara fisik maupun psikologis untuk mencapai tujuan pendidikannya melalui lembaga pendidikan. Butuh waktu yang lama dalam membentuk kepribadian yang baik atau akhlakul karimah terhadap siswa. Banyak hal yang harus dilakukan dalam membentuk kepribadian tersebut, salah satunya dan yang sangat penting adalah penanaman nilai- nilai Islam terhadap anak sejak dini yang kelak akan selalu diingat dan diamalkan ketika mereka beranjak dewasa. Apalagi derasnya arus globalisasi dan bebasnya pergaulan merupakan tantangan besar bagi para pendidik termasuk guru dalam mendidik siswanya.

Pembinaan akhlak sangatlah penting mengingat perkembangan zaman, kemajuan ilmu pengetahuan dan teknologi yang diiringi dengan efek negatif yang tidak bisa kita elakkan, seperti perkelahian antar pelajar, narkoba, pemerkosaan, dan sebagainya. Hal tersebut berakar pada pembinaan akhlak anak di masa kecilnya termasuk pada usia sekolah dasar.

Inilah yang menjadi tanggung jawab guru di sekolah untuk membina dan mendidik mental anak secara lahiriyah dan bathiniyah. Guru, terutama guru PAl harus mampu melaksanakan fungsinya sebagai sarana yang memberikan motivasi, fasilitas edukatif, wahana pengembangan potensi yang ada 
pada diri peserta didik dan mengarahkannya untuk mampu bernilai efektif dan efesien sesuai perkembangan zamannya, serta memberikan bimbingan dan perhatian yang serius terhadap kebutuhan moral-spiritual peserta didiknya. Bimbingan yang dimaksud meliputi pengembangan potensi anak didik, transformasi ilmu pengetahuan, kecakapan (skill), dan mengembangkan nilai-nilai Islam dengan membangkitkan motivasi seoptimal mungkin.

Namun harus kita ketahui bahwa sebagus apapun suatu sekolah, seprofesional apapun gurugurunya tetap harus ada kerjasama dengan pihak keluarga dan masyarakat karena ketiga pihak inilah yang harus saling bersinergi agar tujuan kita dalam membentuk anak- anak yang gemilang bisa tercapai, termasuk dalam hal menanamkan nilai- nilai Islam kepada anak harus secara kontinyu dan konsisten bisa dilakukan oleh ketiga pihak ini.

\section{METODE PENELITIAN}

Penelitian ini merupakan penelitian lapangan (Field Research) dengan pendekatan kualitatif. Menurut Cholid Narbuko (2003: 47) penelitian ini bertujuan mempelajari secara intensif latar belakang kondisi sekarang dan interaksi lingkungan suatu unit sosial, individu, kelompok, lembaga atau masyarakat.

\section{PEMBAHASAN DAN HASIL PENELITIAN}

\section{A. Urgensi Pembinaan Akhlak}

Secara bahasa kata akhlak berasal dari bahasa Arab khuluqun yang berarti al- sajiyah (perangai), altabi'ah (tabiat), al- adat (kebiasaan), al- munu'ah (adab yang baik).

Firman Allah Swt. dalam QS. al-Qalam [68] : 4 sebagai berikut :

$$
\text { وَإِنَّكَ لَعَلَنَ خُلقِ عَظِيمِ }
$$

"Dan Sesungguhnya kamu (Muhammad) benar-benar berbudi pekerti yang agung"

Kata خُلْقُ menurut Prof. Dr. Quraish Shihab (2002: 380) adalah budi pekerti yang luhur, tingkah laku dan watak terpuji. Beliau melanjutkan bahwa manusia memiliki sisi baik dan buruk yakni ketakwaan dan kedurhakaan, tetapi ditemukan isyarat- isyarat dalam al- Quran bahwa kebajikan lebih dahulu menghiasi diri manusia daripada kejahatan dan manusia pada dasarnya cenderung pada kebajikan. (Quraish Shihab: 254)

Pembinaan akhlak merupakan tumpuan perhatian utama dalam ajaran Islam sebagaimana salah satu misi kerasulan nabi Muhammad Saw. yaitu menyempurnakan akhlak mulia. Olehnya itu siswa sangat diharapkan mampu memiliki akhlak mulia sejak dini sehingga setiap perilaku dan aktifitasnya tidak pernah keluar dari ajaran Islam dan cara untuk mencapai tujuan tersebut adalah adanya pembinaan akhlak yang efektif dan berkualitas.

Sebagaimana dikutip oleh Zahruddin (2004: 7-8) bahwa beberapa tujuan pembinaan akhlak meliputi :

I) Agar terbiasa melakukan sesuatu yang baik dan menghindari sesuatu yang buruk

2) Agar hubungan kita dengan Allah dan sesama makhluk selalu terpelihara dengan baik dan harmonis

3) Memantapkan rasa keagamaan pada siswa, membiasakan diri berpegang pada

akhlak mulia dan membenci akhlak yang tercela

4) Membiasakan siswa bersikap rela, optimis, percaya diri, mengendalikan

emosi, tahan menderita, dan sabar

5) Membimbing siswa ke arah sikap yang sehat yang dapat membantu mereka berinteraksi sosial dengan baik, mencintai kebaikan untuk orang lain, suka menolong, saling menyayangi dan menghargai orang lain.

6) Membiasakan siswa bersopan santun dalam berbicara dan bergaul, baik di sekolah maupun di luar sekolah

7) Selalu tekun beribadah dan mendekatkan diri kepada Allah dan bermu'amalah yang baik.

Howard Kirschenbaun menguraikan cara meningkatkan moralitas (akhlak) di sekolah yang dikelompokkan ke dalam lima metode :

$\begin{array}{lrrr}\text { I) Inculcating } & \text { values } & \text { and } & \text { morality } \\ \text { (penanaman } & \text { nilai- } & \text { nilai } & \text { dan }\end{array}$ moralitas)

2) Modelling values and morality (pemodelan nilai- nilai dan moralitas)

3) Facilitating values and morality (memfasilitasi nilai- nilai dan moralitas)

4) Skills value development and moral literacy (keterampilan dalam pengembangan nilai dan literasi moral)

5) Developing a values education program (mengembangkan program pendidikan nilai).

Dari beberapa pendapat tersebut maka diahrapkan semua guru, terutama guru Pendidikan Agama Islam untuk meningkatkan kualitas pembelajaran di sekolah dengan cara menanamkan nilai- nilai moral. Tak hanya itu guru harus menjadi teladan dalam arti harus memberikan contoh dalam mengamalkan nilai- nilai tersebut. Guru juga harus merancang pembelajaran di dalam dan di luar kelas yang dapat memfasilitasi siswa agar bisa membiasakan akhlak mulia.

\section{B. Tugas dan Tanggung Jawab Guru PAI}

Guru mempunyai peran dan kedudukan yang sangat penting dan strategis dalam 
pembangunan nasional dibidang pendidikan. Sebagai mana salah satu tujuan nasional yang tertulis didalam UUD 1945 alenia ke-4 yaitu mencerdaskan kehidupan bangsa. H.M Arifin (1976: I2I) menyatakan bahwa guru-guru yang menjalankan tugasnya sudah tentu harus sanggup menjadikan dirinya sebagai sarana penyampaian cita-cita kepada anak yang telah diamanatkan kepadanya. Dikutip dari buku Ahmad Tafsir (1992: 74-75) bahwa pendidik dalam Islam adalah orang-orang yang bertanggung jawab terhadap perkembangan anak didik dengan mengupayakan perkembangan seluruh potensi anak didik, baik potensi afektif, potensi kognitif, maupun potensi psikomotorik.

Guru PAI adalah penopang perkembangan religiusitas siswa, sehingga guru PAl dituntut untuk memiliki karakteristik sebagai berikut :

I) Kepribadian yang mantap (akhlak mulia) seperti jujur, bertanggung jawab, komitmen terhadap tugas, disiplin, kreatif, dsb.

2) Menguasai disiplin ilmu dalam bidang studi pendidikan agama Islam. Memiliki pemahaman yang memadai tentang bidang studi yang diajarkan, minimal materi yang terkandung dalam kurikulum.

3) Memahami ilmu- ilmu lain yang relevan atau menunjang kemampuannya dalam mengelola proses belajar mengajar seperti psikologi pendidikan, bimbingan dan

konseling, metodologi pendidikan, administrasi pendidikan, teknik evaluasi, dan psikologi agama.

Selain itu yang tak kalah penting adalah bagaimana guru PAI menggunakan metode pembelajaran yang adaptif dengan strategi yang efektif.

\section{Strategi Guru PAI SDN Barambang II, Maros- Sulsel}

Pelaksanaan strategi guru PAl dalam pembinaan akhlak siswa SDN 234 Barambang II sesungguhnya bisa dikelompokkan menjadi dua yaitu secara kontinyu (berkelanjutan) dan temporal (pada waktu tertentu).

\section{Proses Pembelajaran Intrakurikuler \\ a. Variasi dalam pembelajaran PAI}

Aktifitas siswa yang lebih banyak di dalam kelas menuntut guru untuk mampu mengendalikan suasana dan terampil membuat kondisi belajar yang menyenangkan dan tidak membosankan. Keterampilan menggunakan variasi adalah suatu keterampilan mengajar yang harus dikuasai guru dengan tujuan untuk menghilangkan kebosanan siswa dan kejenuhan siswa dalam menerima bahan pengajaran yang diberikan guru serta untuk mengacu dan mengingat perhatian siswa sehingga siswa dapat aktif dan terpartisipasi dalam belajarnya.
Beberapa strategi guru PAl dalam variasi pembelajaran di antaranya :

Penggunaan boneka muslim

Menyanyikan lagu dan yel- yel

islami

Mind mapping bergambar

Pengawasan ketat dalam pemberian tugas

b. Pembiasaan akhlakul karimah

Pembiasaan adalah cara yang ditempuh oleh sekolah untuk membiasakan anak didik/ siswanya melaksanakan ajaran-ajaran agama Islam sehingga mampu mewujudkan tujuan mata pelajaran PAI dan memberikan bekal bagi jiwa keberagamaan siswa selanjutnya.

\section{c. Keteladanan}

Dalam berlangsungnya proses pendidikan metode keteladanan dapat diterapkan dalam dua bentuk, yaitu secara langsung (direct) dan secara tidak langsung (indirect).Secara langsung (direct) maksudnya bahwa guru benar-benar mengaktualisasikan dirinya sebagai contoh teladan yang baik bagi anak didik. Selain secara langsung,metode keteladanan juga dapat diterapkansecara tidak langsung (indirect) maksudnya guru memberikan teladan kepada siswa dengan cara menceritakan kisah-kisah teladan baik itu yang berupa riwayat para nabi, kisah-kisah orang besar, pahlawan dan syuhada, yang bertujuan agar mereka menjadikan tokoh-tokoh tersebut sebagai suriteladan dalam kehidupan mereka.

d. Penegakan tata tertib

Menegakkan tata tertib di sekolah harus dimulai dari unsur/ kelompok sekolah itu sendiri, yakni kepala sekolah, guru dan siswa serta unsur formal lainnya. Guru harus mematuhi tata tertib yang dibuat oleh sekolah dan diimplementasikan dalam interaksinya bersama siswa- siswa, seperti datang tepat waktu, menjaga kebersihan, bertutur kata yang sopan, saling menghargai, saling menghormati, menunjukkan sikap empati, dll.

e. Pembacaan surah pendek sebelum
pembelajaran
Membaca surah pilihan memberi kedamaian tersendiri tatkala siswa bersama- sama membacanya dan Allah kelak akan memberkahi proses pembelajaran yang sedang berjalan karena memulai aktifitas dengan berdo'a dan membaca firman Nya tentu akan beroleh keberkahan dari Allah Swt.

f. Pembiasaan shalat dhuhur berjama'ah

Kebutuhan akan program shalat berjamaah di sekolah terasa penting mengingat melalui cara inilah para guru dapat memantau perkembangan siswa dari banyak hal secara langsung. Shalat berjamaah juga bisa dijadikan sarana untuk mengevaluasi aspek pembelajaran pelajaran agama di kelas yang meliputi aspek kognitif, afektif, dan psikomotorik.

2. Proses pembelajaran ekstrakurikuler

a. Pelaksanaan pesantren kilat 
Pesantren kilat di sekolah ini dilaksanakan selama 3 hari di minggu pertama di bulan suci Ramadhan dengan program dan susunan materi yang sudah diatur sebelumnya. Pesertanya adalah siswa kelas tinggi sedangkan pembawa materinya adalah guru- guru di sekolah itu sendiri.

b. Peringatan maulid Nabi Muhammad Saw.

Kegiatan ini merupakan momentum yang berpengaruh terhadap perkembangan keagamaan siswa, sekaligus menjadi momen untuk memperingati hari lahir Nabi Muhammad Saw. Siswa menyukai keramaian dan kegiatan yang semarak karena akan menambah pengetahuan dan pengalaman mereka apalagi kegiatan maulid hanya dilaksanakan sekali setahun di sekolah sehingga siswa berusaha untuk ikut dalam peringatan seperti ini.

Proses pembinaan dalam pembelajaran intrakurikuler terlaksana setiap hari dan secara berkesinambungan, sedangkan pembinaan dalam pembelajaran ekstrakurikuler hanya dilaksanakan di waktu- waktu tertentu dalam rangka membentuk siswa yang berakhlakul karimah (berakhlak mulia).

\section{PENUTUP}

Pembinaan akhlak sangatlah penting mengingat perkembangan zaman, kemajuan ilmu pengetahuan dan teknologi yang diiringi dengan efek negatif yang tidak bisa kita elakkan, seperti perkelahian antar pelajar, narkoba, pemerkosaan, dan sebagainya. Hal tersebut berakar pada pembinaan akhlak anak di masa kecilnya termasuk pada usia sekolah dasar.

Strategi guru PAI dalam membina akhlak siswa terdiri dari 2 bentuk pembinaan yaitu pembinaan intrakurikuler dan pembinaan ekstrakurikuler. Pembinaan intrakurikuler dilakukan setiap hari dan membutuhkan koordinasi yang konsisten agar berjalan optimal. Sedangkan pembinaan ekstrakurikuler dilakukan pada waktu tertentu.

Pembinaan akhlak siswa tidak hanya menjadi tugas Guru PAl sepenuhnya tetapi semua pihak yang terlibat, termasuk kepala sekolah, guruguru kelas, pegawai sekolah, orang tua siswa, dan warga masyarakat sekitar agar tujuan dalam membentuk siswa yang berakhlakul karimah bisa tercapai secara maksimal.

Akhirnya, diharapkan para guru Pendidikan Agama Islam (PAl), bisa lebih bersemangat dan mengembangkan kompetensinya baik dalam pembelajaran intrakurikuler maupun ekstrakurikuler dalam rangka pembinaan akhlak siswa ke arah yang terbaik yaitu pencapaian akhlakul karimah bagi tiap siswa.

Adapun bagi para penentu kebijakan dalam pendidikan agar kiranya selalu menyelenggarakan sosialisasi atau kegiatan- kegiatan formal dengan para guru, utamanya guru PAl sebagai guru yang lebih bertanggung jawab atas akhlak siswa dengan kegiatan- kegiatan yang mengarah kepada usaha- usaha serta strategi yang tepat dalam rangka pembinaan akhlak siswa tanpa mengesampingkan pengembangan pengetahuan dan keterampilan yang dimiliki oleh seluruh siswa.

\section{DAFTAR PUSTAKA}

Arifin, H. M. 1976. Hubungan Timbal Balik, Pendidikan agama di Lingkungan Sekolah dan Keluarga. Jakarta: Bulan Bintang

Arifin, M. Filsafat Pendidikan Islam. 1987. Jakarta: Bina Aksara

Abdullah, Yatimin. 2007. Studi Akhlak dalam

Perspektif Al- Qur'an. Jakarta: Amzah

Isna, Mansur. 200 I. Diskursus Pendidikan Islam.

Yogyakarta : Global Pustaka Utama

Khalimi. 2006. Berakidah Benar Berakhlak Mulia. Yogyakarta: Pustaka Insan Madani

Narbuko, Cholid. 2003. Metodologi Penelitian.

Jakarta: Bumi Aksara

Nawawi, Hadari. 1989. Organisasi Sekolah dan Pengelolaan Kelas. Jakarta: CV. Haji Mas Agung

Susilaningsih. 2004. Perkembangan Religiuitas pada Anak, disajikan dalam Diskusi IImiah dosen Fakultas Tarbiyah IAIN Sunan Kalijaga. Yogyakarta

Sudino, Anas. Cet. I. Pengantar Evaluasi Pendidikan, Jakarta: Raja Grafindo

Persada,

Sya'rumi. 2007. Model Relasi Ideal Guru dan Siswa : Tela'ah atas Pemikiran Al- Zarnuji dan K.H. Hasyim Asy'ari. Yogyakarta : Teras

Ramdhani, Muhammad Tri, LASTARIA LASTARIA, and ARIYADI ARIYADI. "PEMBELAIARAN EKONOMI DALAM ISLAM PADA MATERI SYIRKAH DI PONDOK PESANTREN." Proceeding Antasari International Conference. Vol. I. No. I. 2020.

Ramdhani, Muhammad Tri, Lastaria Lastaria, and Ariyadi Ariyadi. "Pembelajaran Ekonomi dalam Islam pada Materi Mudharabah di Pondok Pesantren." Anterior Jurnal 19.1 (2019): 32-40. 